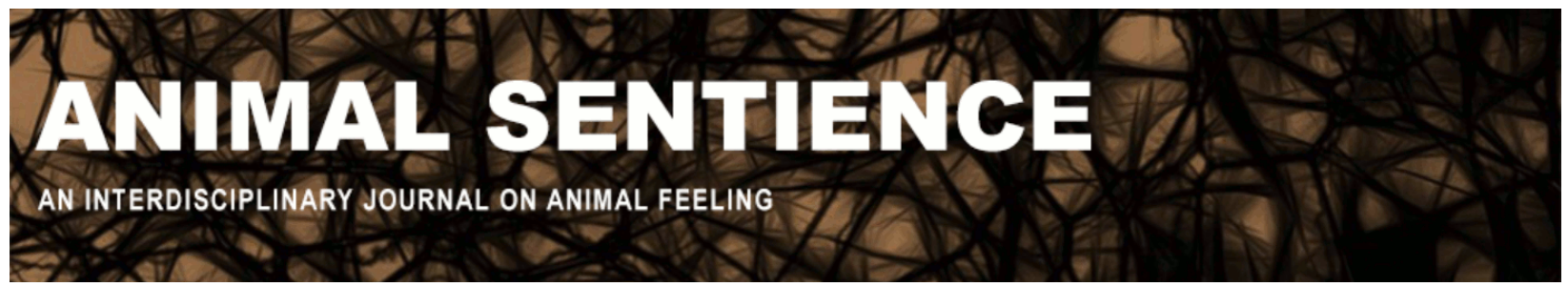

Creson, Thomas (2017) Animal models, agendas and sentience. Animal Sentience 13(10)

DOI: $10.51291 / 2377-7478.1249$

Date of submission: $2017-11-10$

Date of acceptance: 2017-11-13

(c)

This article has appeared in the journal Animal

Sentience, a peer-reviewed journal on animal

cognition and feeling. It has been made open access,

free for all, by WellBeing International and deposited

in the WBI Studies Repository. For more information,

please contact

wbisr-info@wellbeingintl.org.

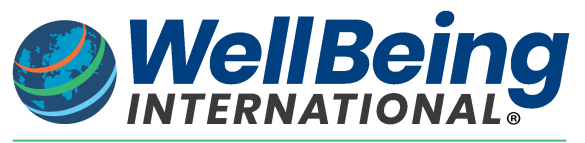

SOLUTIONS FOR PEOPLE, ANIMALS AND ENVIRONMENT 


\title{
Animal models, agendas and sentience
}

Commentary on Woodruff on Fish Feel

\author{
Thomas Creson \\ Department of Neuroscience \\ The Scripps Research Institute Florida
}

\begin{abstract}
Woodruff's target article on teleost consciousness is a well-organized logical argument for considering the fish as a sentient being. This becomes more important for animal ethical discussion as the fish becomes a more important and legitimate animal model for investigating animal states and traits associated with higher levels of behavior such as learning and memory.
\end{abstract}

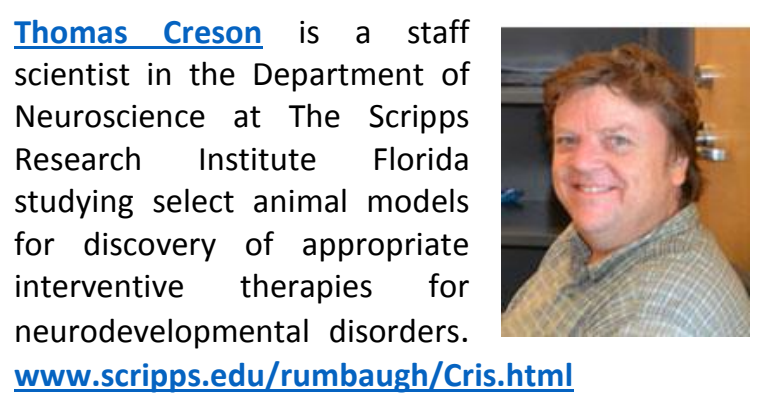

Animal models are typically used to characterize various human disorders and to provide preclinical or translational guides for the discovery of appropriate therapies. A good animal model may exhibit face validity, predictive validity, or construct validity if, respectively, the animal presents with symptoms like those in the human condition, the animal responds to drugs or interventions as the human does, and similar mechanisms can explain the animal and human symptoms and/or their response to a medication or therapy.

The animal model researcher uses a minimalist approach: an animal that is adequate to run a set of experiments yielding meaningful results. The animal should be suited to run tests in a context it can negotiate and in which it has various options to which it can respond. The researcher is also concerned with having at least some level of neuroanatomical, neurophysiological and neurochemical homologies that allow for appropriate comparisons to the human condition. One could argue that the animal does not need to be sentient to react to certain conditions in an experimental context, yet this argument falls apart when the experimental context presents contingencies that the animal must weigh to make choices which require subjective awareness. Fish or other animals serving as models may not understand reasons for being placed into experimental contexts, yet they are able to negotiate choices placed before them and they generally adapt to experimental contexts if needed. The animal, then, must understand at some level that it is separate from the context with which it must negotiate. This distinction would at least imply sentience on behalf of the negotiator.

In Summary 2.3, Woodruff (2017) states, simply and elegantly, that the brain structural criteria for sentience are just that - criteria - not sentience itself. He includes a nice logical 
progression of arguments to conclude that the fish optic tectum meets criteria as a physical substrate for sentience which he breaks down nicely with the archer fish example, a map of the visual world as background with neuronal capacity for attention to stimuli that differ from the background map or template.

Critics of this hypothesis attempt to equate neural structures of so-called lower vertebrates with those of mammals without matching animal agendas with their brain structures. Nature is logical in that animals are not strapped with unnecessary equipment that they may not use in their environments. Animals are equipped so that they can navigate efficiently and procure from their environments what they need to survive and propagate. Fish and mammals certainly have different agendas in handling their environments for the necessities of survival.

Researchers have debated whether rodents have a prefrontal cortex (PFC) at all because theirs is agranular and amorphic relative to higher mammals (Preuss, 1995). Does this mean they do not have a PFC or that the area we are trying to homologize is just different and sufficient to deal with rodents' agendas? With technological advances, it has become apparent that mouse PFC is differentiated for various functional roles. It is interconnected with various subcortical regions not previously considered, such as the amygdala, a circuitry important in associative memories that allow animals to approach or avoid situations well enough to promote survival, etc. Woodruff extends this structural reasoning to the fish tectum and pallidum using the excellent work with goldfish from the researchers at the Universidad de Sevilla concerning DM/amygdala and DL/hippocampus homologies. Here, a normal fish can perform adequately in a shuttle box avoidance paradigm that requires the subjective sense of fear, yet the DM-lesioned fish cannot. Similarly, the performance of DL-lesioned fish in declarative memory paradigms such as an allocentric spatial learning task is impaired.

Creson et al. (2003) used a Poeciliid (black molly) animal model to show that lithium administration compromises cognitive processes. With a convertible $\mathrm{T} /+$ water maze, we showed that working memory (spontaneous alternation) and spatial memory (rewarded place test) were compromised by lithium in a dose-dependent fashion. Although these fish did have limitations in their capacity to perform variants of these tests, they provided a useful animal model to answer questions driven by hypothesis-based testing. The egocentric and temporal nature of the working memory task, as well as the allocentric and temporal nature of the spatial task, required the fish to be conscious of their place whether using proprioceptive cues or cues distinct from themselves within a purposeful context.

\section{References}

Creson, T.K., Woodruff, M.L., Ferslew, K.E., Rasch, E.M., and Monaco, P.J. (2003). Dose-response effects of chronic lithium regimen on spatial memory in the black molly fish. Pharmacology, Biochemistry and Behavior, 75, 35-47.

Preuss, T.M. (1995). Do rats have prefrontal cortex? The Rose-Woolsey-Akert program reconsidered. Journal of Cognitive Neuroscience, 7(1), 1-24.

Woodruff, M.L. (2017). Consciousness in teleosts: There is something it feels like to be a fish. Animal Sentience 13(1). 


\section{ANIMAL CONSCIOUSNESS}

On November 17-18, 2017, the NYU Center for Mind, Brain and Consciousness, the NYU Center for Bioethics, and NYU Animal Studies will host a conference on Animal Consciousness.

This conference will bring together philosophers and scientists to discuss questions such as: Are invertebrates conscious? Do fish feel pain? Are nonhuman mammals self-conscious? How did consciousness evolve? How does research on animal consciousness affect the ethical treatment of animals? What is the impact of issues about animal consciousness on theories of consciousness and vice versa? What are the best methods for assessing consciousness in nonhuman animals?

\section{Speakers and panelists include:}

Colin Allen (University of Pittsburgh, Department of History \& Philosophy of Science), Andrew Barron (Macquarie, Cognitive Neuroethology), Victoria Braithwaite (Penn State, Biology), Peter Carruthers (Maryland, Philosophy), Marian Dawkins (Oxford, Zoology), Dan Dennett (Tufts, Philosophy), David Edelman (San Diego, Neuroscience),

Todd Feinberg (Mt. Sinai, Neurology), Peter Godfey-Smith (Sydney, Philosophy), Lori Gruen (Wesleyan, Philosophy), Brian Hare (Duke, Evolutionary Anthropology), Stevan Harnad (Montreal, Cognitive Science), Eva Jablonka (Tel Aviv, Cohn Institute), Björn Merker (Neuroscience), Diana Reiss (Hunter,

Psychology), Peter Singer (Princeton, Philosophy), Michael Tye (Texas, Philosophy)

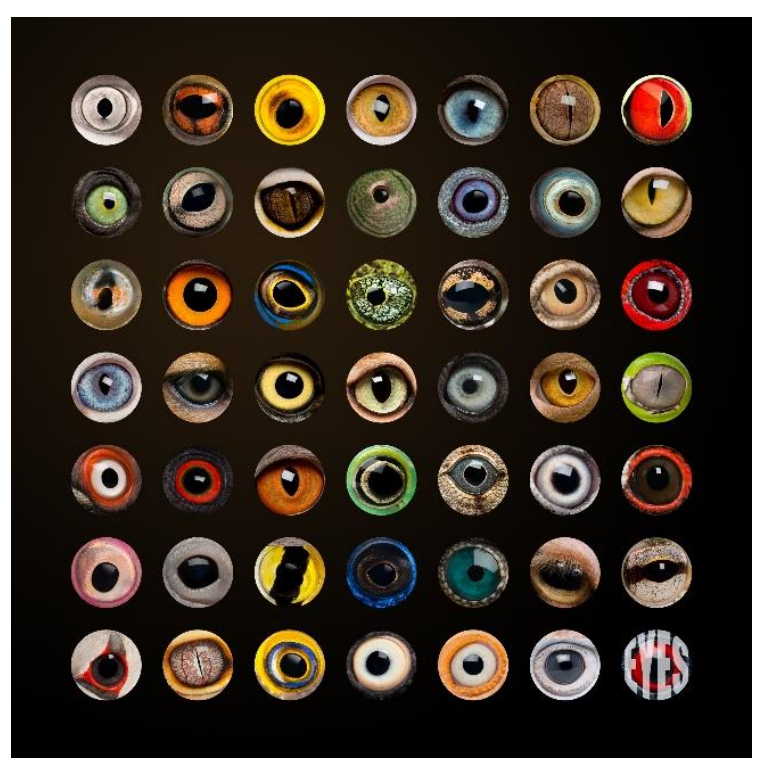

Organizers: Ned Block, David Chalmers, Dale Jamieson, S. Matthew Liao.

The conference will run from 9am on Friday November 17 to $6 \mathrm{pm}$ on Saturday November 18 at the NYU Cantor Film Center (36 E 8th St).

Friday sessions will include "Invertebrates and the evolution of consciousness", "Do fish feel pain?", and "Animal consciousness and ethics".

Saturday sessions will include "Animal self-consciousness", "Animal consciousness and theories of consciousness", and a panel discussion.

A detailed schedule will be circulated closer to the conference date.

Registration is free but required.

\section{Register here.}

\section{See also the conference website}

